\title{
An Electrochemical Sensor Based on Reduced Graphene Oxide Modified Carbon Paste Electrode for Curcumin Determination in Human Blood Serum
}

\author{
Mostafa Rahimnejad ${ }^{a, *}$, Rosan Zokhtareh ${ }^{a}$, \\ Ali Akbar Moghadamnia ${ }^{b}$ and Maryam Asghary ${ }^{c}$ \\ ${ }^{a}$ Biofuel \& Renewable Energy Research Center, Department of Biotechnology, Faculty of \\ Chemical Engineering, Babol Noshirvani University of Technology, Babol, Iran \\ ${ }^{b}$ Department of Physiology \& Pharmacology, Babol University of Medical Sciences, Babol, Iran \\ ${ }^{c}$ Department of Analytical Chemistry, Faculty of Chemistry, \\ University of Mazandaran, Babolsar, Iran
}

Received October 29, 2017; accepted June 12, 2018

\begin{abstract}
A sensitive, accurate electrochemical sensor based on reduced graphene oxide modified carbon paste electrode (RGO/CPE) was developed to measure curcumin levels in human blood serum. The as-prepared electrode (RGO/CPE) was verified to outperform bare carbon paste electrode (CPE), with increased oxidation and reduction peaks at $+0.505 \mathrm{~V}$ and $+0.408 \mathrm{~V}$, respectively. Curcumin measurement was performed using cyclic voltammetry (CV) and differential pulse voltammetry (DPV) techniques. $\mathrm{RGO} / \mathrm{CPE}$ showed a desirable linear response towards curcumin, within the concentration range of $10-6000 \mu \mathrm{M}$; the detection limit $(\mathrm{S} / \mathrm{N}=3)$ was $3.183 \mu \mathrm{M}$. Moreover, electrochemical impedance spectroscopy (EIS) and field emission scanning electron microscope (FESEM) were applied to gain further insight into the electrochemical behavior of the proposed electrode. The results revealed that the usage of RGO caused increased sensitivity of the sensor response to curcumin; therefore, $\mathrm{RGO} / \mathrm{CPE}$ can be considered a promising electrochemical sensor for curcumin determination in human blood serum.
\end{abstract}

Keywords: curcumin, reduced graphene oxide, carbon paste electrode, electrochemical sensor, differential pulse voltammetry.

\section{Introduction}

Curcumin is derived from a plant called Turmeric, which belongs to the ginger family [1]. In addition to being a spice, preservative, and a coloring agent, it has been known for thousands of years for its wide range of applications in treating different types of diseases [2-4]. The main origin of turmeric plant is eastern India and China. However, it is also cultivated in many tropical areas, such as

\footnotetext{
* Corresponding author. E-mail address: rahimnejad_mostafa@yahoo.com
} 
Malaysia, Indonesia, Pakistan, Africa and South America [5-7]. The yellow color of turmeric is mainly due to a group of polyphenols called curcuminoids. Curcumin, demethoxycurcumin and bisdemethoxycurcumin are the curcuminoids in turmeric, which are different in terms of substitution of the methoxy group on the aromatic rings in the turmeric structure [8-10]. Curcumin is the most active component of turmeric, and it is also its main therapeutic agent [11-12].

Following various studies on the therapeutic benefits of curcumin, it has been found that this compound has anti-inflammatory [13], antibacterial [14] and antioxidant properties [15], and it can heal wounds and infections [16]. In addition, curcumin has also been used against diseases, including allergies, depression, colitis, diabetes, nephrotoxicity, Alzheimer, psoriasis, cardiovascular diseases, multiple sclerosis (MS), and AIDS [17-20].

Active oxygen radicals, including the anions of superoxide and hydroxyl radicals, are involved in the development of arteriosclerosis and carcinogenesis. Therefore, removing these active radicals is effective in preventing cardiovascular diseases, as well as cancers [21-23]. In comparison to vitamins C and $\mathrm{E}$, curcumin has a far more powerful antioxidant activity, and results in the synthesis inhibition of free radicals, as well as in their deactivation and removal [24-25].

One of the most important properties of curcumin is its high potential in preventing the development of cancers, and helping in the treatment of these diseases, as well as decreasing the unwelcome chemotherapy side effects [2627]. Curcumin performs its anticancer activity inhibiting inflammatory pathways, stopping cellular cycles, inducing apoptosis, and inhibiting angiogenesis, as well as metastasis in cancerous cells [28]. This compound has proved to be effective in treating a wide variety of cancers, including blood, prostate, uterus, lung, liver, kidney, ovarian, and pancreatic cancers [29-31].

Considering the positive characteristics of curcumin, and its role in preventing and treating different diseases, it is quite important to find an effective identification method for its determination. Various analytical methods have so far been used for the detection of this compound, including high performance liquid chromatography [32], capillary electrophoresis [33], ultraviolet visible spectroscopy [34], spectrofluorimetry [35], resonance light scattering [36], and electrochemical methods [36-37].

Among these methods, electrochemical sensors have enjoyed a great popularity, due to their fast response, low cost, simple operation, high sensitivity, and suitable selectivity [36, 38-39]. However, due to curcumin weak response with traditional electrochemical sensors, its direct measurement has always been a matter of controversy. Thus, it has been preferable to electrochemically measure it using modified electrodes [37, 40-41]. Accordingly, finding appropriate compounds with high stability, good catalytic activity and excellent conductivity to modify the electrodes has always been a real challenge.

Graphene has well-organized, layered carbon atoms with $\mathrm{sp}^{2}$ hybrid in a honeycomb configuration, and two dimensional crystal networks [42]. Unique characteristics, such as a flat two dimensional structure, high mechanical and chemical stability, large surface area, low cellular toxicity, favorable 
productivity, and suitable biocompatibility, have introduced graphene as a desirable compound for electrochemical uses [42-43]. In comparison with other carbon allotropes, graphene's high surface area allows it to be applied in electrochemically used nanocomposites [44]. Graphene-modified electrochemical sensors have been employed for the determination of compounds such as glucose, heavy metal ions, cholesterol, pesticides, etc. [42, 45].

In this study, a sensitive electrochemical sensor was fabricated for curcumin detection, by benefiting from reduced graphene oxide as modifier for a CPE surface. The electrochemical behavior of curcumin was studied at the surfaces of bare $\mathrm{CPE}$ and $\mathrm{RGO} / \mathrm{CPE}$, and it was revealed that curcumin oxidation and reduction peaks currents significantly increased at the modified electrode surface, comparing to those of the bare CPE. This can indicate the improved sensitivity in curcumin measurement with RGO as modifier.

\section{Experimental}

\section{Reagents and apparatus}

Using graphite powder as the main raw material, graphene oxide (GO) was synthesized via a modified Hummers' method [46]. Briefly, graphite (5 g) and $\mathrm{NaNO}_{3}(2.5 \mathrm{~g})$ were mixed with $120 \mathrm{~mL}$ of $\mathrm{H}_{2} \mathrm{SO}_{4}$ in a $500 \mathrm{~mL}$ flask. The mixture was stirred for 30 min within an ice bath. While maintaining vigorous stirring, $\mathrm{KMnO}_{4}(15 \mathrm{~g})$ was added to the suspension, and the reaction temperature was kept lower than $20^{\circ} \mathrm{C}$. The mixture was then stirred at room temperature overnight.

Afterwards, $150 \mathrm{~mL}$ of $\mathrm{H}_{2} \mathrm{O}$ were slowly added to the pasty, with vigorous agitation. The reaction temperature was rapidly increased to $98{ }^{\circ} \mathrm{C}$, and the diluted suspension was stirred at that temperature for one day. Then, $50 \mathrm{~mL}$ of 30 $\% \mathrm{H}_{2} \mathrm{O}_{2}$ were added to the mixture. Graphite oxide was isolated from the mixture by centrifugation, and washed with a solution of $5 \% \mathrm{HCl}$ and deionized (DI) water. Finally, the solid product was dried at $60{ }^{\circ} \mathrm{C}$ for 2 days.

To reduce GO, a total of $0.5 \mathrm{~g}$ of the synthesized GO was mixed with $200 \mathrm{~mL}$ of DI water, and underwent ultrasonic procedure for $40 \mathrm{~min}$. Then, $5 \mathrm{~mL}$ of hydrazine were added to the mixture, which was stirred for $24 \mathrm{~h}$ in a paraffin bath at $40{ }^{\circ} \mathrm{C}$, in order for GO to be reduced and changed into RGO.

Curcumin was purchased from Merck (Germany), and a stock solution of $1.0 \times 10^{-2} \mathrm{M}$ was prepared using ethanol as solvent. A phosphate buffer solution (PBS 0.1 M, pH 3) containing $1 \mathrm{M}$ sodium chloride was used as electrolyte. All the solutions used throughout the experiments were prepared just prior to the experiments, via diluting the stock solution. All other reagents were of analytical grade, and used without retreatment. All the solutions were prepared using DI water.

The electrochemical experiments were performed using a potentiostat/ galvanostat device (IVIUM TECHNOLOGY-VERTEX, Netherlands) and an electrochemical cell. The cell was constituted of CPE modified with RGO as working electrode, a platinum wire as counter electrode, and an $\mathrm{Ag} / \mathrm{AgCl}$ 
electrode as reference electrode. FESEM imaging was carried out by Mira 3XMU field emission SEM with an acceleration potential of $15 \mathrm{kV}$.

\section{Preparation of CPE and RGO/CPE}

To prepare CPE, graphite powder and paraffin oil were mixed within the ratio of 70:30 (w/w), and then well pulverized in a mortar to obtain a homogeneous carbon paste. The as-prepared paste was transferred to a glass tube, and a copper wire was used to compress it and establish electric connection. Before the electrode fabrication, the utilized glass tube was fully smoothed and uniformed using fine sandpaper, and then washed with distilled water. Before each experiment, the electrode was polished on a soft paper, so that a fully smoothed surface would be obtained. To prepare the modified electrode, an optimized amount of RGO was added to the graphite powder, in order to obtain a carbon paste containing $7 \% \mathrm{RGO}$.

\section{Results and discussion}

\section{Characterization of CPE and RGO/CPE using FESEM}

The surface morphology and the size of RGO nanoparticles were identified by FESEM. FESEM images of graphite and RGO are demonstrated in Fig. 1. As it can be seen, graphite sheets have been separately stacked on top of each other and in a layered fashion (Fig. 1a). On the other hand, graphene sheets were found to be in a bulk state and were clumped to each other, which can be due to the repulsion developed between them, in response to the reduction with hydrazine (Fig. 1b). The size of the RGO nanoparticles was estimated to be within the ranges of $20-40 \mathrm{~nm}$.

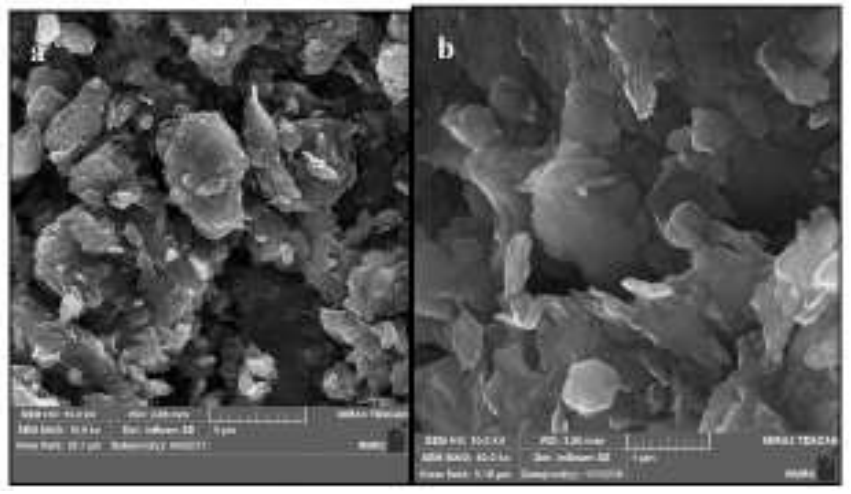

Figure 1. FESEM images of (a) CPE and (b) RGO/CPE.

\section{Electrochemical characterization of CPE and RGO/CPE}

In order to investigate the structure and electrochemical characteristics of $\mathrm{CPE}$ and RGO/CPE, as well as to study the changes in the electric resistance, Fig. 2 shows, at the bare CPE surface, a semicircle with a large radius $\left(\mathrm{R}_{\mathrm{et}}=5.226 \mathrm{k} \Omega\right.$ ) connected to a straight line. At the RGO/CPE surface, only one straight line can be seen; this demonstrates diminished electron transfer resistance at the $\mathrm{RGO/CPE}$ surface versus bare CPE surface. This can be due to graphene's 
electro-activity and large surface area. Based on the results, it can be deduced that graphene addition to CPE plays a significant role in enhancing the conductivity and sensitivity of this electrode; thus, RGO/CPE can considerably increase the electron transfer rate.

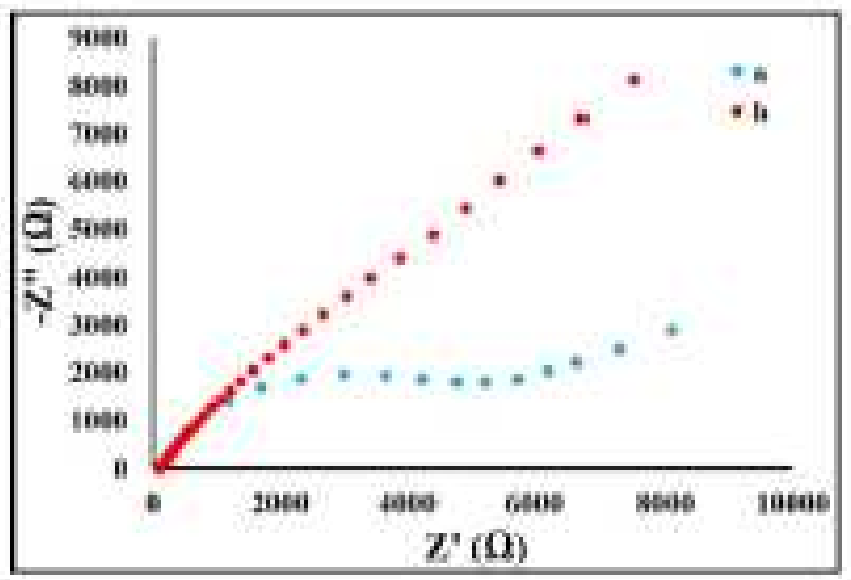

Figure 2. EIS of (a) bare CPE and (b) RGO/CPE in 0.1 M PBS (pH 3) containing 1.0 $\mathrm{mM} \mathrm{K}_{3}\left[\mathrm{Fe}(\mathrm{CN})_{6}\right] / 1.0 \mathrm{mM} \mathrm{K}_{4}\left[\mathrm{Fe}(\mathrm{CN})_{6}\right]$ and $0.1 \mathrm{M} \mathrm{KCl}$ (frequency range: $10^{5}$ to 0.1 $\mathrm{Hz}$; potential: $0.18 \mathrm{~V}$ ).

\section{Curcumin electrochemical behavior at RGO/CPE}

As Fig. 3a shows, in comparison with the blank voltammograms (curve c), in the first cycle (curve a), an oxidation peak $\left(\mathrm{p}_{1}\right)$ and a reduction peak $\left(\mathrm{p}_{2}\right)$ can be seen at the potentials of $+0.530 \mathrm{~V}$ and $+0.339 \mathrm{~V}$, respectively. In the second cycle (curve $b$ ), the oxidation peak of the first cycle $\left(\mathrm{p}_{1}\right)$ disappeared, and a new oxidation peak $\left(\mathrm{p}_{3}\right)$ substituted it at the potential of $+0.494 \mathrm{~V}$, while the reduction peak $\left(\mathrm{p}_{2}\right)$ did not show any change.

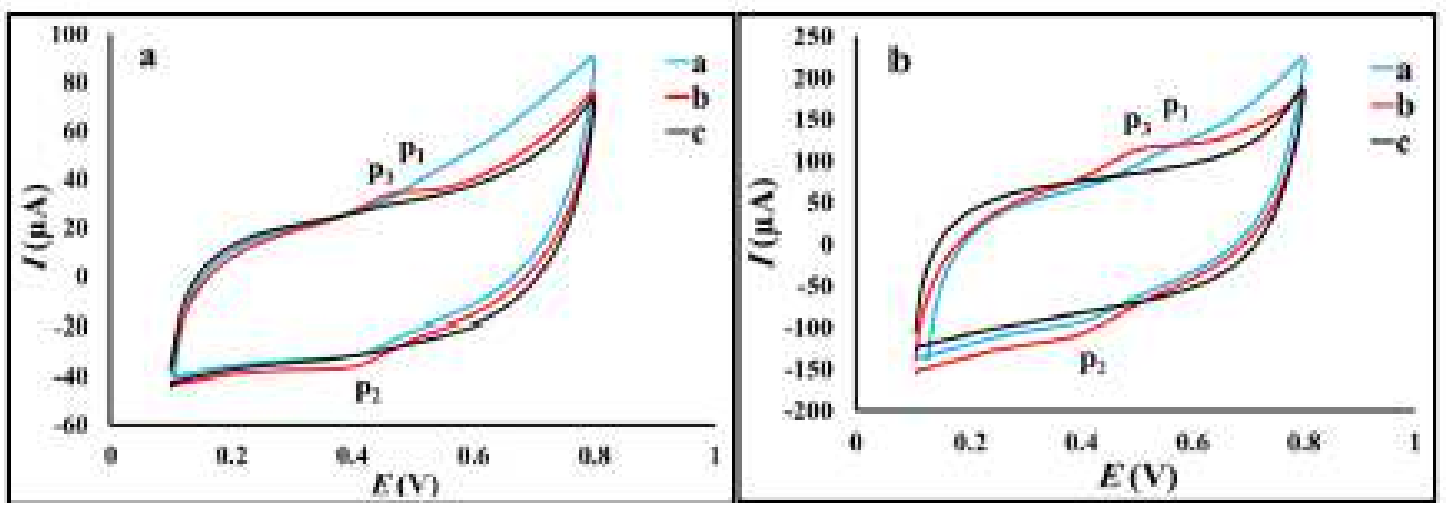

Figure 3. $\mathrm{CVs}$ of $1.0 \times 10^{-4} \mathrm{M}$ curcumin in $0.1 \mathrm{M}$ PBS (pH 3) over two cycles at (a) bare $\mathrm{CPE}$ and (b) RGO/CPE, at the scan rate of $100 \mathrm{mV} \mathrm{s}^{-1}$ (a: first cycle; b: second cycle). Curve $\mathrm{c}$ displays the blank voltammograms.

The results imply that, in the first cycle, curcumin may possibly convert into an intermediate compound by losing one proton and two electrons. In the second cycle, on the other hand, this intermediate compound underwent oxidation and reduction, with transference of two electrons and two protons; this process was 
reversibly repeated $[37,45]$. According to Fig. $3 b$, the electrochemical behavior of curcumin at $\mathrm{RGO} / \mathrm{CPE}$, in comparison with $\mathrm{CPE}$, follows a completely similar pattern, yet shows a slight difference at the surface of the modified electrode, where a significant increase in the oxidation and reduction peaks can be observed. This suggests high RGO's catalytic ability in the oxidation and reduction of curcumin. A reasonable electrochemical reaction mechanism was suggested, which can be seen in Scheme 1.
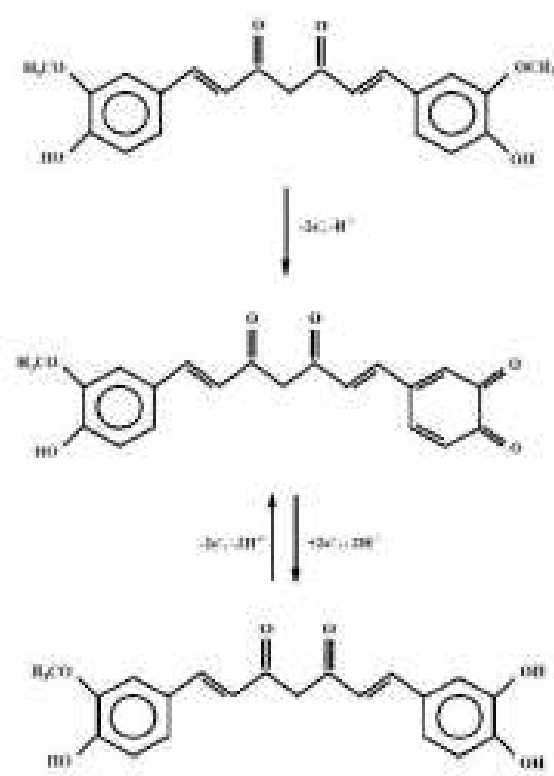

Scheme 1. Proposed curcumin's electrochemical reaction mechanism.

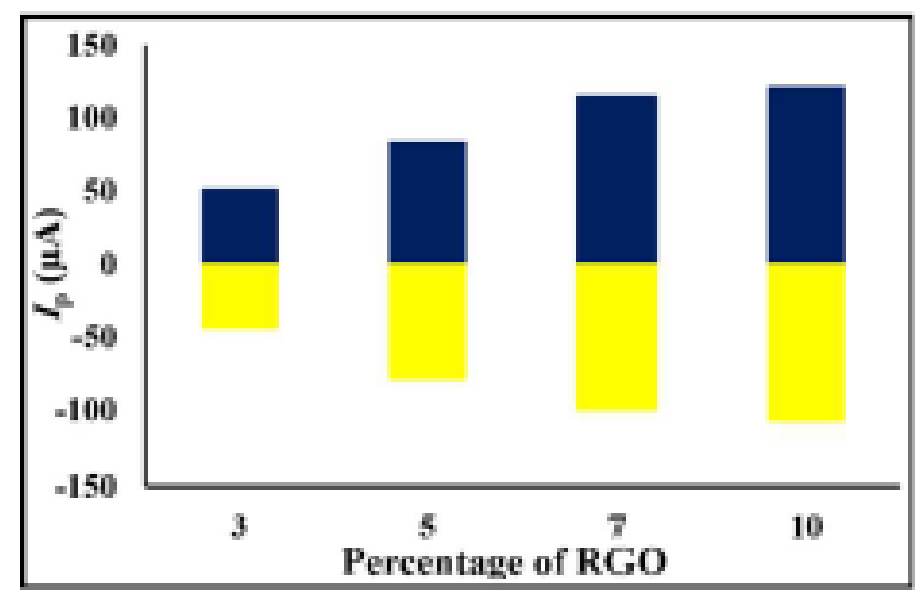

Figure 4. Effect of RGO quantity on the oxidation $\left(\mathrm{P}_{3}\right)$ and reduction $\left(\mathrm{P}_{2}\right)$ peaks of $1.0 \times 10^{-4} \mathrm{M}$ curcumin in $0.1 \mathrm{M}$ PBS ( $\mathrm{pH} 3$ ), at the scan rate of $100 \mathrm{mV} \mathrm{s}^{-1}$.

Therefore, RGO/CPE containing $7 \%$ RGO was chosen as working electrode to further study the electrochemical behavior of curcumin.

\section{Determining the optimal amount of $R G O$}

Owing to RGO's high catalytic ability in the oxidation and reduction of curcumin, the determination of the optimal RGO value used in CPE configuration is essential to achieve the highest efficiency, and enhance the sensor's sensitivity. Accordingly, CPEs containing different RGO percentages (3, 
5, 7, and $10 \%$ ) were prepared, and the effect of these varied amounts was examined on the electrochemical oxidation and reduction peaks of $1.0 \times 10^{-4} \mathrm{M}$ curcumin, in the second cycle, at RGO/CPE, using $\mathrm{CV}$. The results showed that, with the increase in RGO's amount up to $7 \%$, the oxidation and reduction peaks of curcumin increased and, afterwards, they remained constant (Fig. 4).

\section{Effect of scan rate}

Fig. 5a illustrates the CVs of $1.0 \times 10^{-4} \mathrm{M}$ curcumin at RGO/CPE, at different scan rates (v) $\left(20-120 \mathrm{mV} \mathrm{s}^{-1}\right)$.
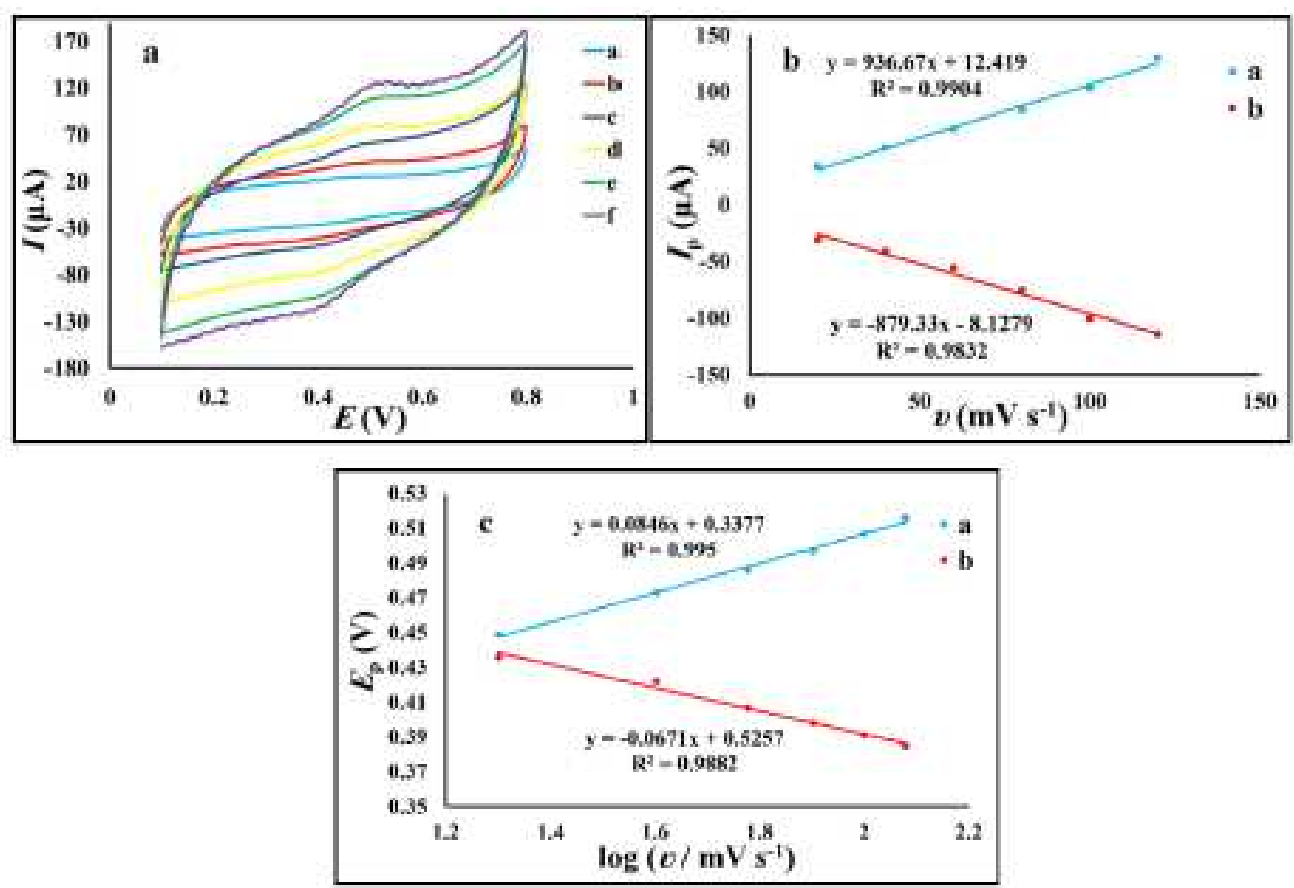

Figure 5. (a) CVs of $1.0 \times 10^{-4} \mathrm{M}$ curcumin at RGO/CPE in $0.1 \mathrm{M} P B S(\mathrm{pH} 3$ ) at different scan rates: a) $20 \mathrm{mVs}^{-1}$, b) $40 \mathrm{mVs}^{-1}$, c) $60 \mathrm{mVs}^{-1}$, d) $80 \mathrm{mVs}^{-1}$, e) $100 \mathrm{mVs}^{-1}$, and f) $120 \mathrm{mVs}^{-1}$ ). (b) Relationship between $I_{\mathrm{p}}$ and $v$. (c) Relationship between $E_{\mathrm{p}}$ and $\log v$.

As it can be seen in Fig. 5b, with the increase in the scan rates, the current of oxidation (a) and reduction (b) peaks linearly increases $\left(\mathrm{I}_{\mathrm{pa}}=936.67 \mathrm{v}+12.419\right.$ $\left(\mathrm{R}^{2}=0.9904\right)$ and $\left.\mathrm{I}_{\mathrm{pc}}=-879.33 v-8.1279\left(\mathrm{R}^{2}=0.9832\right)\right)$, suggesting that adsorption controls the electrochemical process of curcumin at RGO/CPE. Furthermore, based on Fig. 5c, the relationship between the potential of oxidation (a) and reduction (b) peaks, as well as the logarithm of the potential scan rate are linear: $\mathrm{E}_{\mathrm{pa}}=0.0846 \log v+0.3377\left(\mathrm{R}^{2}=0.995\right)$ and $\mathrm{E}_{\mathrm{pc}}=-0.0671 \log v+0.5257$ $\left(\mathrm{R}^{2}=0.9882\right)$. The number of transferred electrons $(\mathrm{n})$, electron transfer coefficient $(\alpha)$, and electron transfer rate constant $\left(\mathrm{K}_{\mathrm{s}}\right)$ can be calculated by the following equations, which have been explained by Laviron.

$$
\begin{aligned}
E_{p a} & =2.303 R T /(1-\alpha) n F \\
E_{p c} & =-2.303 R T / \alpha n F
\end{aligned}
$$


$\log K_{S}=\alpha \log (1-\alpha)+(1-\alpha) \log \alpha-\log (R T / n F v)-\alpha(1-\alpha)\left(n F \Delta E_{p} / 2.3 R T\right)$

Benefiting from Eqs. 1 and $2, \mathrm{n}(=1.5)$ and $\alpha(=0.58)$ were calculated, and $\mathrm{K}_{\mathrm{s}}$ was also estimated to be $0.5382 \mathrm{~s}^{-1}$ using Eq. 3 .

\section{Effect of $p H$}

$\mathrm{CV}$ was employed to study $\mathrm{pH}$ effect on curcumin's electrochemical oxidation and reduction. Fig. 6 a displays the CVs of $1.0 \times 10^{-4} \mathrm{M}$ curcumin in $0.1 \mathrm{M}$ PBS, at $\mathrm{RGO} / \mathrm{CPE}$, in the range of $2 \leq \mathrm{pH} \leq 8$, in the second cycle. Based on Fig. $6 \mathrm{~b}$, the maximum current of oxidation (a) and reduction (b) peaks of curcumin at $\mathrm{RGO} / \mathrm{CPE}$ was maintained at $\mathrm{pH} 3$. Thus, this $\mathrm{pH}$ value was considered as optimum. In addition, with the increase in the solution's $\mathrm{pH}$, the potential of oxidation (a) and reduction (b) peaks of curcumin negatively shifted in a linear mode (Fig. 6c): $\mathrm{E}_{\mathrm{pa}}=-0.0469 \mathrm{pH}+0.6664\left(\mathrm{R}^{2}=0.9918\right), \mathrm{E}_{\mathrm{pc}}=-0.0492 \mathrm{pH}+$ $0.5362\left(\mathrm{R}^{2}=0.9908\right)$. These results might suggest that protons were directly involved in the electrochemical oxidation and reduction processes of curcumin. Therefore, Eq. 4 can be used to calculate the ratio of the number of protons to the number of electrons $(\mathrm{m} / \mathrm{n})$. Using this equation, $\mathrm{m} / \mathrm{n}$ was estimated to be 0.79 and 0.83 for the oxidation and reduction processes, respectively, which exhibited the equivalence of the number of electrons and protons exchanged in the electrochemical oxidation and reduction processes of curcumin.

$$
d E_{p} / d_{p H}=2.303 m R T / n F
$$
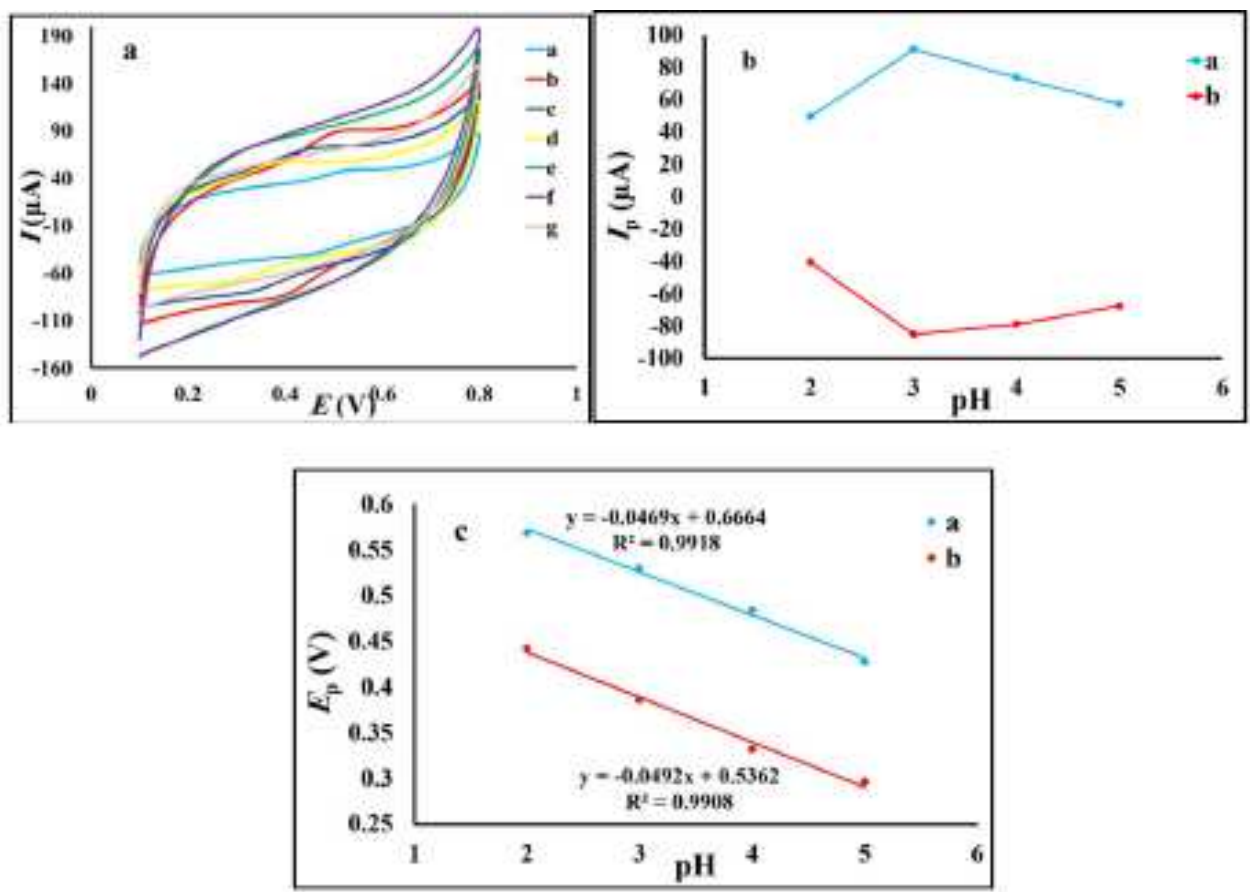

Figure 6. (a) $\mathrm{pH}$ effect on the electrochemical oxidation and reduction of $1.0 \times 10^{-4} \mathrm{M}$ curcumin, at RGO/CPE in $0.1 \mathrm{M}$ PBS, at the scan rate of $100 \mathrm{mVs}^{-1}$. (b) Relationship between $\mathrm{I}_{\mathrm{p}}$ and $\mathrm{pH}$. (c) Relationship between $\mathrm{E}_{\mathrm{p}}$ and $\mathrm{pH}$. $\mathrm{pH}$ of PBS (from curves a to g), respectively: $2,3,4,5,6,7$, and 8 . 


\section{Determination of the detection limit}

To determine the relationship between curcumin concentration and the current resulting from its electrochemical oxidation, differential pulse voltammograms were recorded in solutions with different concentrations $(10-6000 \mu \mathrm{M})$, at RGO/CPE (Fig. 7a). As it can be seen, the increase in curcumin concentration in the solution results in the enhancement of its oxidation peak current. According to Fig. $7 \mathrm{~b}$, it is clear that the changes in the current are linear within the range of $10-100 \mu \mathrm{M}$, based on $\mathrm{I}_{\mathrm{pa}}=0.105 \mathrm{C}+245.19\left(\mathrm{R}^{2}=0.9998\right)$, and within the range of $300-6000 \mu \mathrm{M}$, based on $\mathrm{I}_{\mathrm{pa}}=0.0013 \mathrm{C}+257.62\left(\mathrm{R}^{2}=0.9982\right)$. The detection limit was also calculated to be $3.183 \mu \mathrm{M}$. The replicability of this method was measured by preparing 5 electrodes, and investigating their response to $1.0 \times 10^{-4}$ $\mathrm{M}$ curcumin, with the relative standard deviation (RSD) estimated as $2.8 \%$. Furthermore, five separated experiments were performed using one electrode, and the estimated RSD was $3.6 \%$. These results can prove that RGO/CPE enjoys a favorable replicability for curcumin determination. In order to ensure RGO/CPE stability, this electrode was put aside for 7 days, and after this period, it was able to develop $96.3 \%$ of the initial response in the $1.0 \times 10^{-4} \mathrm{M}$ curcumin solution, under similar circumstances. The comparison of RGO/CPE with other curcumin electrochemical sensors in the reported literatures is listed in Table 1.

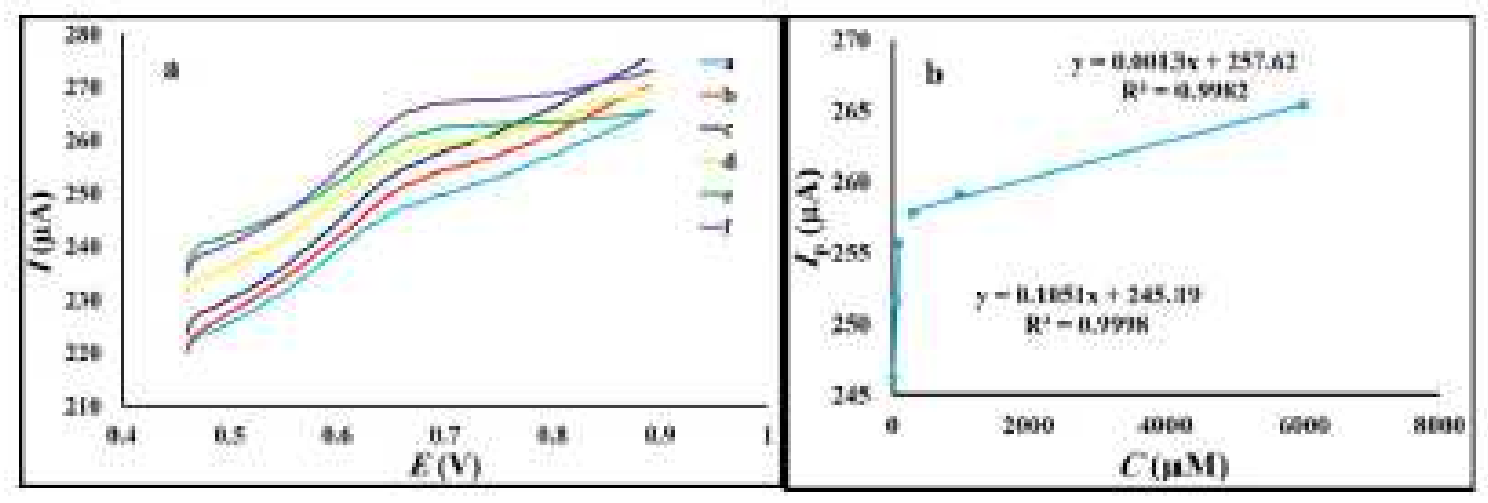

Figure 7. (a) DPVs of various curcumin concentrations (a) 10, b) 60, c) 100, d) 300, e) 1000 , and f) $6000 \mu \mathrm{M}$ ) at $\mathrm{RGO} / \mathrm{CPE}$ in $0.1 \mathrm{M} \mathrm{PBS}(\mathrm{pH} \mathrm{3})$, at the scan rate of 100 $\mathrm{mVs}^{-1}$. (b) Curcumin's calibration curve.

Table 1. Comparison of the performance of curcumin's electrochemical sensors.

\begin{tabular}{|cccccc|}
\hline Electrode & $\begin{array}{c}\text { Electrochemical } \\
\text { technique }\end{array}$ & $\mathbf{p H}$ & $\begin{array}{c}\text { Linear range } \\
(\boldsymbol{\mu M})\end{array}$ & $\mathbf{L O D}(\boldsymbol{\mu M})$ & Reference \\
\hline $\mathrm{SPCE}$ & $\mathrm{AdSV}[\mathrm{a}]$ & $0.1 \mathrm{M} \mathrm{HCl}$ & $2.2-280$ & 4.9 & {$[47]$} \\
\hline $\mathrm{GCE}$ & $\mathrm{CV}$ & $0.1 \mathrm{M} \mathrm{LiClO}_{4}$ & $9.9-107$ & 4.1 & {$[48]$} \\
\hline $\mathrm{NiCl}_{2} / \mathrm{GCE}$ & $\mathrm{DPV}$ & $4(0.1 \mathrm{M} \mathrm{PBS})$ & $10-600$ & 0.109 & {$[49]$} \\
\hline $\mathrm{ERGO} / \mathrm{GCE}$ & $\mathrm{DPV}$ & $7.4(0.1 \mathrm{M} \mathrm{PBS})$ & $0.2-60$ & 0.1 & {$[45]$} \\
\hline $\mathrm{GR} / \mathrm{GCE}$ & $\mathrm{LSV}[\mathrm{b}]$ & $0.1 \mathrm{M} \mathrm{H}_{2} \mathrm{SO}_{4}$ & $0.05-3.0$ & 0.03 & {$[37]$} \\
\hline
\end{tabular}

[a] Differential pulse adsorptive stripping voltammetry. [b] Linear sweep voltammetry. 


\section{Analysis of curcumin spiked in human blood serum}

In order to investigate the efficiency of the designed sensor in measuring curcumin in real samples, RGO/CPE was used to determine curcumin level in human blood serum. Firstly, experimental solutions were prepared from blood serum containing different curcumin concentrations and, then, the DPVs of the samples diluted with $0.1 \mathrm{M}$ PBS $(\mathrm{pH} 3)$ were recorded. The evaluation of the recovery level of curcumin was performed by the standard addition method, of which results are provided in Table 2 .

Table 2. Determination results of curcumin in human blood serum.

\begin{tabular}{|ccccc|}
\hline Sample & Added $(\boldsymbol{\mu M})$ & Found $(\boldsymbol{\mu M})$ & RSD $(\boldsymbol{\%}, \mathbf{n}=\mathbf{3})$ & Recovery $(\boldsymbol{\%})$ \\
\hline 1 & 10 & 9.98 & 3.9 & 99.8 \\
\hline 2 & 60 & 60.06 & 4 & 100.1 \\
\hline 3 & 100 & 99.9 & 4.8 & 99.9 \\
\hline
\end{tabular}

\section{Interference studies}

Selectivity is one of the most important characteristics of an electrochemical sensor, and represents the extent of its ability in detecting a specific analyte in the presence of other chemical and biological compounds. To examine RGO/CPE selectivity, CV was used to measure the sensor's ability in detecting curcumin in the presence of $\mathrm{K}^{+}, \mathrm{Cu}^{2+}, \mathrm{Ni}^{2+}$ ions, as well as of sucrose and glucose. Throughout the experiments, curcumin's concentration was kept constant $\left(1.0 \times 10^{-4} \mathrm{M}\right)$, and the external compounds were spiked into the cell containing the experimental solution with a certain concentration (100 times as large as curcumin concentration). The results indicated that, with $\mathrm{K}^{+}, \mathrm{Cu}^{2+}, \mathrm{Ni}^{2+}$, sucrose, and glucose addition, no inhibition in curcumin detection was developed (Fig. 8).

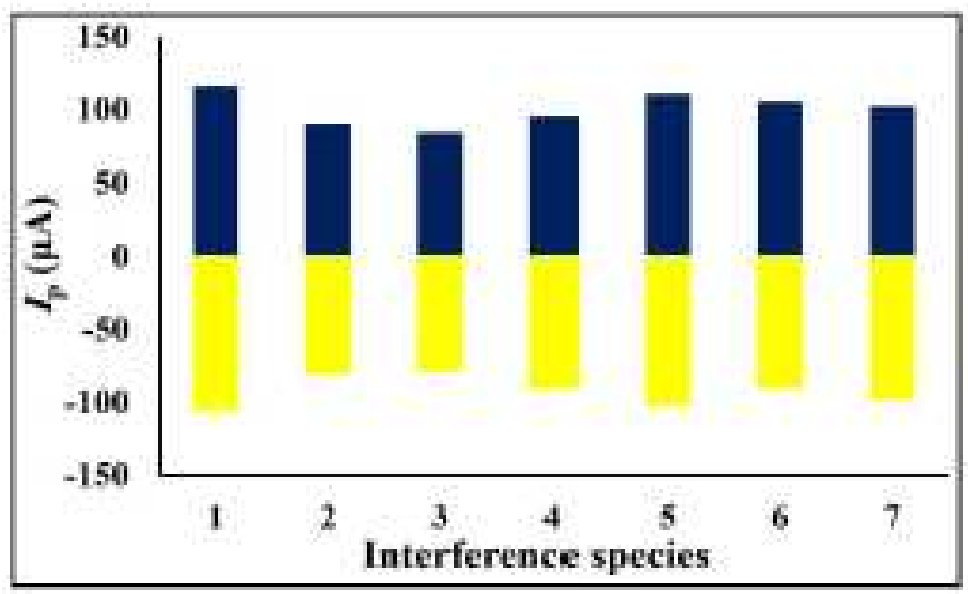

Figure 8. Effect of the interference species on the oxidation and reduction peaks of $1.0 \times 10^{-4} \mathrm{M}$ curcumin at RGO/CPE, and at the scan rate of $100 \mathrm{mVs}^{-1}$ in $0.1 \mathrm{M}$ PBS $(\mathrm{pH}$ 3) by $\mathrm{CV}$. From 1 to 7: curcumin, 100- fold $\mathrm{K}^{+}, \mathrm{Cu}^{2+}, \mathrm{Ni}^{2+}$, sucrose, glucose, and all compounds. 


\section{Conclusion}

In this study, using the unique characteristics of RGO, a sensitive and reliable electrochemical method was proposed for measuring curcumin in human blood serum. In comparison with bare CPE, the modified electrode indicated a significant capability in increasing the current of oxidation and reduction peaks. This can be due to graphene's favorable conductivity and large surface area. CV and DPV methods were employed to examine curcumin's electrochemical behavior at RGO/CPE. Results revealed that the adsorption may most likely control the electrochemical process of curcumin at its surface. The obtained detection limit was $3.183 \mu \mathrm{M}$. The proposed modified electrode exhibited an acceptable replicability and catalytic activity towards curcumin. The modified RGO/CPE also showed reasonable storage stability. Considering appropriate recoveries provided by the designed sensor, it can be used in human blood serum for curcumin determination, with acceptable results.

\section{References}

1. Lal J. Turmeric, curcumin and our life: a review. Bull Environ Pharmacol Life Sci. 2012;1:11-7.

2. Krishnakumar I, Kumar D, Ninan E, et al. Enhanced absorption and pharmacokinetics of fresh turmeric (Curcuma Longa L) derived curcuminoids in comparison with the standard curcumin from dried rhizomes. J Funct Foods. 2015;17:55-65.

3. Dweck AC. Natural ingredients for colouring and styling. International J Cosmetic Sci. 2002;24:287-302.

4. Aditya N, Aditya S, Yang H-J, et al. Curcumin and catechin co-loaded waterin-oil-in-water emulsion and its beverage application. J Funct Foods. 2015;15:35-43.

5. Hatcher H, Planalp R, Cho J, et al. Curcumin: from ancient medicine to current clinical trials. Cellular Molec Life Sci. 2008;65:1631-52.

6. Roth GN, Chandra A, Nair MG. Novel bioactivities of Curcuma longa constituents. J Nat Prod. 1998;61(4):542-5.

7. Debjit Bhowmik C, Kumar KS, Chandira M, et al. Turmeric: a herbal and traditional medicine. Arch Appl Sci Res. 2009;1:86-108.

8. Anand P, Kunnumakkara AB, Newman RA, et al. Bioavailability of curcumin: problems and promises. Molec Pharmac. 2007;4:807-18.

9. Priyadarsini KI. The chemistry of curcumin: from extraction to therapeutic agent. Molecules. 2014;19:20091-112.

10. Kim Y-J, Lee HJ, Shin Y. Optimization and validation of high-performance liquid chromatography method for individual curcuminoids in turmeric by heat-refluxed extraction. J Agric Food Chem. 2013;61:10911-8.

11. Shishodia S, Sethi G, Aggarwal BB. Curcumin: getting back to the roots. Annals New York Acad Sci. 2005;1056:206-17.

12. Pulido-Moran M, Moreno-Fernandez J, Ramirez-Tortosa C, et al. Curcumin and health. Molecules. 2016;21:264.

13. Singh S. From exotic spice to modern drug? Cell. 2007;130:765-8. 
14. Gunes H, Gulen D, Mutlu R, et al. Antibacterial effects of curcumin: an in vitro minimum inhibitory concentration study. Toxicology Ind Health. 2016;32:246-50.

15. Dhakal S, Chao K, Schmidt W, et al. Evaluation of turmeric powder adulterated with metanil yellow using FT-Raman and FT-IR spectroscopy. Foods. 2016;5:36.

16. Krausz AE, Adler BL, Cabral V, et al. Curcumin-encapsulated nanoparticles as innovative antimicrobial and wound healing agent. Nanomedicine: Nanotechnology, Biology Medicine. 2015;11:195-206.

17. Prasad S, Gupta SC, Tyagi AK, et al. Curcumin, a component of golden spice: from bedside to bench and back. Biotech Adv. 2014;32:1053-64.

18. Beevers CS, Huang S. Pharmacological and clinical properties of curcumin. Botanics: Targets Therapy. 2011;1:5-18.

19. Aggarwal BB, Kumar A, Aggarwal MS, et al. Curcumin derived from turmeric (Curcuma longa): a spice for all seasons. Phytopharmac Cancer Chemoprevention. 2005;23:351-87.

20. Nishiyama T, Mae T, Kishida H, et al. Curcuminoids and sesquiterpenoids in turmeric (Curcuma longa L.) suppress an increase in blood glucose level in type 2 diabetic KK-Ay mice. J Agric Food Chem. 2005;53:959-63.

21. Labban L. Medicinal and pharmacological properties of Turmeric (Curcuma longa): A review. Int J Pharm Biomed Sci. 2014;5:17-23.

22. Sreejayan N, Rao M, Priyadarsini K, et al. Inhibition of radiation-induced lipid peroxidation by curcumin. Int J Pharmac. 1997;151:127-30.

23. Sharma R, Gescher A, Steward W. Curcumin: the story so far. Eur J Cancer. 2005;41:1955-68.

24. Maheshwari RK, Singh AK, Gaddipati J, et al. Multiple biological activities of curcumin: a short review. Life Sciences. 2006;78:2081-7.

25. Aggarwal BB, Kumar A, Bharti AC. Anticancer potential of curcumin: preclinical and clinical studies. Anticancer Research. 2003;23:363-98.

26. $\mathrm{Yu} \mathrm{H}$, Huang Q. Enhanced in vitro anti-cancer activity of curcumin encapsulated in hydrophobically modified starch. Food Chem. 2010;119:669-74.

27. Boon H, Wong J. Botanical medicine and cancer: a review of the safety and efficacy. Expert Opin Pharmacotherapy. 2004;5:2485-501.

28. Sarkar FH, Li Y, Wang Z, et al. Lesson learned from nature for the development of novel anti-cancer agents: implication of isoflavone, curcumin, and their synthetic analogs. Current Pharmaceutical Design. 2010;16:1801-12.

29. Anand P, Sundaram C, Jhurani S, et al. Curcumin and cancer: an "old-age" disease with an "age-old" solution. Cancer Letters. 2008;267:133-64.

30. Jurenka JS. Anti-inflammatory properties of curcumin, a major constituent of Curcuma longa: a review of preclinical and clinical research. Alternative Medicine Rev. 2009;14.

31. López-Lázaro M. Anticancer and carcinogenic properties of curcumin: considerations for its clinical development as a cancer chemopreventive and chemotherapeutic agent. Molec Nutrition Food Res. 2008;52. 
32. Heath DD, Pruitt MA, Brenner DE, et al. Curcumin in plasma and urine: quantitation by high-performance liquid chromatography. J Chromatog $B$. 2003;783:287-95.

33. Lechtenberg M, Quandt B, Nahrstedt A. Quantitative determination of curcuminoids in Curcuma rhizomes and rapid differentiation of Curcuma domestica Val. and Curcuma xanthorrhiza Roxb. by capillary electrophoresis. Phytochemical Analysis. 2004;15:152-8.

34. Tang B, Ma L, Wang H-y, et al. Study on the supramolecular interaction of curcumin and $\beta$-cyclodextrin by spectrophotometry and its analytical application. J Agric Food Chem. 2002;50:1355-61.

35. Wang F, Huang W. Determination of curcumin by its quenching effect on the fluorescence of $\mathrm{Eu}^{3+}$-tryptophan complex. J Pharmac Biomed Anal. 2007;43:393-8.

36. Peng J, Nong K, Cen L. Electropolymerization of acid chrome blue $\mathrm{K}$ on glassy carbon electrode for the determination of curcumin. J Chinese Chem Soc. 2012;59:1415-20.

37. Li K, Li Y, Yang L, et al. The electrochemical characterization of curcumin and its selective detection in Curcuma using a graphene-modified electrode. Analyt Methods. 2014;6:7801-8.

38. Ezoji H, Rahimnejad M. Electrochemical Determination of Bisphenol A on Multi-Walled Carbon Nanotube/titanium dioxide Modified Carbon Paste Electrode. Int J Sci Res. 2016;7:242-6.

39. Heli H, Jabbari A, Majdi S, et al. Electrooxidation and determination of some non-steroidal anti-inflammatory drugs on nanoparticles of $\mathrm{Ni}$-curcumincomplex-modified electrode. J Solid State Electrochem. 2009;13:1951.

40. Daneshgar P, Norouzi P, Moosavi-Movahedi AA, et al. Fabrication of carbon nanotube and dysprosium nanowire modified electrodes as a sensor for determination of curcumin. J Appl Electrochem. 2009;39:1983.

41. Arslan E, Çakır S. A novel palladium nanoparticles-polyproline-modified graphite electrode and its application for determination of curcumin. J Solid State Electrochem. 2014;18:1611-20.

42. Bahadır EB, Sezgintürk MK. Applications of graphene in electrochemical sensing and biosensing. TrAC Trends Analyt Chem. 2016;76:1-14.

43. Shao Y, Wang J, Wu H, et al. Graphene based electrochemical sensors and biosensors: a review. Electroanalysis. 2010;22:1027-36.

44. Ruecha N, Rodthongkum N, Cate DM, et al. Sensitive electrochemical sensor using a graphene-polyaniline nanocomposite for simultaneous detection of $\mathrm{Zn}$ (II), Cd (II), and Pb (II). Analyt Chim Acta. 2015;874:40-8.

45. Zhang D, Ouyang X, Ma J, et al. Electrochemical behavior and voltammetric determination of curcumin at electrochemically reduced graphene oxide modified glassy carbon electrode. Electroanalysis. 2016;28:749-56.

46. Paulchamy B, Arthi G, Lignesh B. A simple approach to stepwise synthesis of graphene oxide nanomaterial. J Nanomedicine Nanotech. 2015;6:1.

47. Wray DM, Batchelor-McAuley C, Compton RG. Selective Curcuminoid Separation and Detection via Nickel Complexation and Adsorptive Stripping Voltammetry. Electroanalysis. 2012;24:2244-8. 
48. Ziyatdinova G, Nizamova A, Budnikov H. Voltammetric Determination of Curcumin in Spices. J Analyt Chem. 2012; 67:591-4.

49. Zokhtareh R, Rahimnejad M. A Novel Sensitive Electrochemical Sensor Based on Nickel Chloride Solution Modified Glassy Carbon Electrode for Curcumin Determination. Electroanalysis. 2018; 2018;30:921-7. 